\title{
A high incidence of polymorphic CYP2C19 variants in archival blood samples from Papua New Guinea
}

\author{
Huai-Ling Hsu,' Kathryn J. Woad, ${ }^{2}$ D. Graeme Woodfield' and Nuala A. Helsby',3* \\ ${ }^{\prime}$ Department of Molecular Medicine and Pathology, University of Auckland, Private Bag 92019, Auckland, New Zealand \\ ${ }^{2}$ Discipline of Oncology, University of Auckland, Private Bag 92019, Auckland, New Zealand \\ ${ }^{3}$ Auckland Cancer Society Research Centre, University of Auckland, Private Bag 92019, Auckland, New Zealand \\ *Correspondence to: Tel: +649373 7599 (ext 89831); Fax: +649373 7492; E-mail: n.helsby@auckland.ac.nz
}

Date received (in revised form): 7th March, 2008

\begin{abstract}
There is considerable inter-ethnic variability in the incidence of CYP2C19 genetic poor metabolisers (var/var). About 3 per cent of Caucasians are CYP2C19 var/var. By contrast, an extremely high incidence (70 per cent) is observed in the Melanesian island of Vanuatu. The colonisation of the Pacific Islands is believed to have involved migration through Papua New Guinea (PNG), and hence a high incidence may also be expected in this population. The reported incidence in PNG was only 36 per cent, however. PNG is a country of extensive ethnic diversity, and the incidence of the CYP2C 19 var/var in other regional populations of PNG is currently not established. In this study, restriction fragment length polymorphism-polymerase chain reaction analysis of archival blood serum samples was used to determine the prevalence of the CYP2C19*2 and *3 variant alleles in three different ethnic and geographically isolated populations of PNG. In the largest population studied (Iruna), the frequency of both variant CYP2CI 9 alleles was high ( 0.37 and 0.34 , respectively). Specifically, the frequency of the CYP2CI9*3 allele was significantly higher than in the PNG (East Sepik) population reported previously (0.34 vs $0.16 ; p<0.000 \mathrm{I})$. In the Iruna population, 48.9 per cent of the samples were homozygous variants for CYP 2 C 1 $9 * 2$ or $* 3$, which although higher was not statistically different from the East Sepik population (36 per cent). The results of this study indicated that other regional populations of PNG also have a relatively high incidence of the CYP2CI9 genetic polymorphism compared with Caucasian populations. The high incidence reported in Vanuatu, however, may be due to genetic drift rather than a PNG founder population, as the Vanuatu population is dominated by the CYP2C19*2 allele, with a lower contribution from the $* 3$ allelic variant.
\end{abstract}

Keywords: CYP2C19 genetic variants, ethnic variability, Papua New Guinea

\section{Introduction}

Poor metabolism of drugs, such as the anti-malarial agent proguanil ${ }^{1}$ and the anti-ulcer agent omeprazole $^{2}$ is associated with genetic variants of the CYP2C19 enzyme (CYP2C19*2 and CYP2C19*3). ${ }^{3}$ The CYP2C19*2 (c.681G > A) variant results in a splice site mutation ${ }^{4}$ and the CYP2C19*3 (c.636G > A) variant results in a premature stop codon ${ }^{4}$ and both result in a loss of functional enzyme. There is a gene dose-dependent decrease in drug metabolism, and individuals who are homozygous wild-type, heterozygous or homozygous variant for these null alleles are termed extensive (EM), intermediate (IM) or poor (PM) metabolisers.

The restriction fragment length polymorphismpolymerase chain reaction (RFLP-PCR) analysis of these variant alleles is widely used and well validated. It is also clearly established that the $* 2$ and *3 null alleles account for the majority of 
phenotypic $\mathrm{PMs}^{5}$ and that the $* 3$ null allele is specific to Asian populations and is extremely rare in Caucasian populations. ${ }^{3}$

There is considerable inter-ethnic variation in the distribution of the CYP2C19 genetic polymorphism, with an incidence of the homozygous variant of $\sim 3$ per cent in Caucasians ${ }^{5}$ and $\sim 20$ per cent in Asians. ${ }^{6}$ An extremely high frequency (70.6 per cent) has been reported in the Melanesian island of Vanuatu. ${ }^{7}$ Relatively little is known about the incidence in other ethnic populations, however, such as the Melanesians and Polynesians. Anthropological evidence suggests that the people of Vanuatu may have migrated from Papua New Guinea (PNG) about 3,500 years ago. ${ }^{8-11}$ The incidence of the CYP2C19 genetic polymorphism in the East Sepik (northern coast) region of $\mathrm{PNG}$ is reported to be 36 per cent, ${ }^{12}$ which, although higher than in Caucasian populations, is considerably lower than that observed in Vanuatu. PNG is one of the most ethnically diverse regions of the world, however, and the incidence of the CYP2C19 genetic polymorphism in other regional populations of PNG is not currently established. An alternative PNG population may be the source of the high incidence of CYP2C19 variants in Vanuatu.

We report the use of archival serum samples to determine the prevalence of the CYP2C19*2 and $* 3$ variant alleles in three different ethnic and geographically isolated regional populations of PNG. The results of this study may provide further information about the source of the high incidence of the CYP2C19 genetic polymorphism in Vanuatu and may help to determine whether a high incidence can be predicted for other Pacific Island populations.

\section{Materials and methods}

\section{Archival serum samples}

Serum samples were collected as a part of a blood group phenotype survey in PNG over 30 years ago. ${ }^{13,14}$ Samples were from three geographically isolated areas of PNG: Tufi, Iruna and Fly River. PNG has a large ethnic diversity owing to the geographical isolation of the regional populations, and this is associated with a large number of languages. ${ }^{15}$ The languages spoken by people from Tufi, Iruna and Fly River are mutually exclusive. The Fly River samples were collected from the inland Kiunga region in Western province, Iruna samples were collected at the United Church Hospital (Iruna) Magarida in the Central province on the south-east coast of PNG and the Tufi samples were collected from small isolated villages in the Oro (formally, Northern) province on the north-east coast of PNG. The participants gave oral consent to donate their blood voluntarily, as a gift to be used for the welfare of other Papua New Guineans. The samples were transported to Port Moresby, centrifuged (2500 g) for serum collection and then stored at $-20^{\circ} \mathrm{C}$. The serum samples were stored in insulated boxes with dry ice for transportation by air to New Zealand and were then stored at $-80^{\circ} \mathrm{C}$ at the University of Auckland. The use of these samples for analysis of the CYP2C19 genetic polymorphism was approved by the University of Auckland Human Participants Ethics Committee (UoA HPEC 2005/004).

\section{DNA extraction}

Genomic DNA was extracted from serum as previously described, ${ }^{16}$ with minor modifications. Serum $(200 \mu \mathrm{l})$ was incubated with 1 per cent (w/ v) sodium dodecyl sulphate and proteinase $\mathrm{K}$ $(100 \mu \mathrm{g})$ in a $200 \mu \mathrm{l}$ reaction overnight at $55^{\circ} \mathrm{C}$ to denature the protein complexes. DNA was then prepared by phenol/chloroform extraction, followed by ethanol precipitation in the presence of glycogen $(50 \mu \mathrm{g})$ as a co-precipitant. The DNA was air dried $(<20$ minutes) and resuspended in elution buffer $(10 \mathrm{mM}$ Tris-HCl, pH 8.5; $50 \mu \mathrm{l}$; Roche Diagnostics, GmbH, Mannheim, Germany).

\section{Genotyping procedures: PCR}

The CYP2C19*2 and CYP2C19*3 primers used in this study were as previously described, ${ }^{17}$ with minor modification of the CYP2C19*2 reverse primer to 5'-GTAAACACAAAACTAGTCAATG3' (altered base pair [bp] is underlined), as the published primer sequence did not correspond to the CYP2C19 sequence (NT030059.12; Genbank). ${ }^{4}$ 
The PCR Master Mix (Qiagen, New Zealand) used in the amplification reaction contained Taq DNA polymerase (2.5 units), 10X Qiagen PCR buffer containing $1.5 \mathrm{mM}$ magnesium chloride $\left(\mathrm{MgCl}_{2}\right)$, and $200 \mu \mathrm{M}$ of each deoxynucleoside triphosphate (dNTP). The PCR amplification conditions were as previously described, ${ }^{17}$ with minor modifications. The PCR reaction was performed in a $50 \mu \mathrm{l}$ experiment containing $\sim 80 \mathrm{ng}$ of DNA template, $0.5 \mathrm{mM}$ of each $\mathrm{dNTP}, 0.5 \mu \mathrm{M}$ of each primer and $1.5 \mathrm{mM} \mathrm{MgCl} 2$ in $1 \mathrm{X}$ PCR buffer (Qiagen). The amplification conditions were: one cycle of $94^{\circ} \mathrm{C}$ for five minutes (initial denaturation); 37 cycles of $94^{\circ} \mathrm{C}$ for 20 seconds (denaturation), one cycle of $53^{\circ} \mathrm{C}$ for ten seconds (annealing); one cycle of $72^{\circ} \mathrm{C}$ for ten seconds (extension); and one cycle of $72^{\circ} \mathrm{C}$ for five minutes (final extension).

\section{RFLP analysis}

CYP2C19*3 PCR products were subjected to an additional purification step (High Pure PCR product purification kit; Roche Diagnostics $\mathrm{GmbH}$ ) before restriction enzyme digestion to eliminate suspected incomplete Bam HI digestion observed in preliminary experiments. The CYP2C19*2 and CYP2C19*3 PCR products were subjected to SmaI and BamHI restriction enzyme digestion, respectively, as previously described, ${ }^{17}$ with the minor modification that the CYP2C19*2 PCR product $(20 \mu \mathrm{l})$ was incubated with $20 \mathrm{U}$ of SmaI. The RFLP products were analysed by gel electrophoresis on a 3 per cent $(\mathrm{w} / \mathrm{v})$ agarose gel and visualised by staining with ethidium bromide and ultraviolet illumination.

\section{Direct DNA sequencing}

Random samples were subjected to DNA sequencing to confirm that the CYP2C19*2 and CYP2C19*3 genotypes were assigned correctly. Prior to sequencing, the PCR products were purified using the High Pure PCR product purification kit. The ABI PRISM ${ }^{\mathrm{TM}}$ BIG DYE Terminator (BDT) Sequencing Kit, version 3.1 (ABI, Forster City, CA, USA) was used for the DNA sequencing reaction and the product was analysed at the DNA

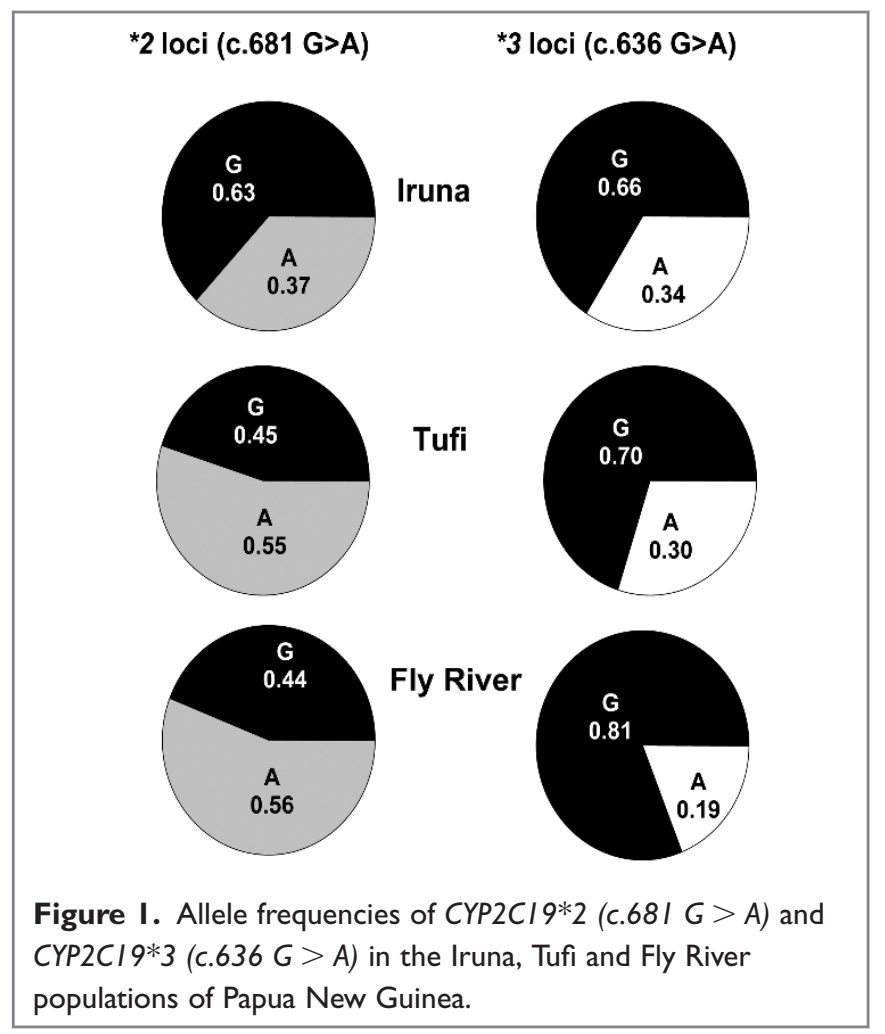

sequencing facility of the Centre of Genomics and Proteomics (University of Auckland, New Zealand) on an ABI PRISM ${ }^{\text {TM }} 3100$ Genetic Analyzer.

\section{Statistical analysis}

Genotype and allele frequencies were calculated from the counts. Expected genotype numbers were calculated using the Hardy-Weinberg equation $\left(p^{2}+2 p q+q^{2}=1\right)$ using the allele numbers, where $q$ is the number of the variant alleles $\left(C Y P 2 C 19^{*} 2\right.$ and $\left.C Y P 2 C 19^{*} 3\right)$ and $p$ is the number of wild-type alleles at the corresponding CYP2C19*2 and CYP2C19*3 loci. The chi-squared test was used to determine if the data were in agreement with the Hardy-Weinberg equilibrium. As the CYP2C19 genotype is closely correlated with the phenotype, the numbers of PMs in the largest population studied (Iruna) was compared with the PM incidence in the previously published East Sepik data, ${ }^{12}$ using the continuitycorrected chi-squared test with 95 per cent confidence interval. 
Table I. The incidence of the CYP2CI9 genotype and predicted phenotype in the Iruna, Tufi and Fly River regions of Papua New Guinea

\begin{tabular}{|c|c|c|c|c|c|c|c|c|c|}
\hline \multicolumn{3}{|c|}{ Genotype } & \multicolumn{3}{|c|}{ Frequency (n) } & \multirow{2}{*}{$\begin{array}{l}\text { Predicted } \\
\text { phenotype }\end{array}$} & \multicolumn{3}{|c|}{ Incidence (\%) } \\
\hline c.68I & c.636 & & Iruna & Tufi & Fly River & & Iruna & Tufi & Fly River \\
\hline G/G & $\mathrm{G} / \mathrm{G}$ & $* I / * I$ & 3 & 0 & I & $\begin{array}{l}\text { Extensive } \\
\text { metaboliser }\end{array}$ & 6.4 & 0 & 12.5 \\
\hline $\mathrm{G} / \mathrm{A}$ & $\mathrm{G} / \mathrm{G}$ & $* \mid / * 2$ & 9 & 2 & 2 & $\begin{array}{l}\text { Intermediate } \\
\text { metaboliser }\end{array}$ & 44.7 & 30 & 25 \\
\hline $\mathrm{G} / \mathrm{G}$ & $\mathrm{G} / \mathrm{A}$ & $* 1 / * 3$ & 12 & 1 & 0 & & & & \\
\hline G/A & $\mathrm{G} / \mathrm{A}$ & $* 2 / * 3$ & 10 & 5 & 3 & $\begin{array}{l}\text { Poor } \\
\text { metaboliser }\end{array}$ & 48.9 & 70 & 62.5 \\
\hline $\mathrm{A} / \mathrm{A}$ & $\mathrm{G} / \mathrm{G}$ & $* 2 / * 2$ & 8 & 2 & 2 & & & & \\
\hline G/G & $\mathrm{A} / \mathrm{A}$ & $* 3 / * 3$ & 5 & 0 & 0 & & & & \\
\hline
\end{tabular}

\section{Results}

Genomic DNA of sufficient quality and quantity was extracted from 65 serum samples across the three regions of PNG (Iruna, $n=47$; Tufi, $n=10$; Fly River, $n=8)$. Amplification of the CYP2C19*2 and CYP2C19*3 target sequence from these archival serum samples resulted in 321 and $271 \mathrm{bp}$ products, respectively. Digestion of the CYP2C19*2 amplicon with SmaI resulted in products of 212 and $109 \mathrm{bp}$ (homozygous wild type; c.681 G/G); 321, 212 and 109 bp (heterozygote; $\mathrm{G} / \mathrm{A})$; and a single undigested product of $321 \mathrm{bp}$ (homozygous *2; A/A). Digestion of the CYP2C19*3 amplicon with BamHI resulted in products of 175 and $96 \mathrm{bp}$ (homozygous wild-type; c. $636 \mathrm{G} / \mathrm{G}$ ); products of 271, 175 and $96 \mathrm{bp}$ (heterozygote *3; G/A); and a single undigested product of $271 \mathrm{bp}$ (homozygous $* 3$; A/A). A total of 45 samples were randomly selected for direct DNA sequencing and there was 100 per cent agreement with the RFLP assignments.

CYP2C19 variant alleles $(* 2$ and $* 3)$ were detected in all three populations studied (Figure 1), with the $* 2$ variant allele $($ c. $681 \mathrm{G}>\mathrm{A})$ ranging in frequency from 0.37 to 0.56 and the $* 3$ variant allele (c.636 G $>$ A) frequency from 0.19 to 0.34 across the three populations. This confirms the high frequency of $* 2$ and $* 3$ alleles observed by Masta et al. ${ }^{12}$ in the East Sepik region of PNG. The distributions of both the CYP2C19*2 and $C Y P 2 C 19^{*} 3$ alleles were in agreement with the
Hardy-Weinberg equilibrium across all three regions (data not shown). Due to the very small sample size for the Tufi $(n=10)$ and Fly River $(n=8)$ populations, however, we have precluded any further data analysis of these regional populations in case these allele frequencies are not representative of the true population frequencies. Therefore, only the data for the Iruna population $(n=47)$ was used for comparison with the published data for the East Sepik region. ${ }^{12}$

There was a significantly higher incidence $(0.34$; $p<0.0001$ ) of the CYP2C19*3 (c.636 G>A) variant allele in the Iruna population compared with the East Sepik population (0.14-0.19). The combined frequency of the $* 2$ and $* 3$ alleles results in a very high total frequency of variants (0.71) and results in a high incidence of the CYP2C19 PM genotype (homozygous and compound heterozygote variant) in the Iruna region of PNG of 48.9 per cent (Table 1). In addition, a high incidence (62.5 and 70 per cent) of the CYP2C19 PM genotype was also observed in the Fly River and Tufi samples, respectively (Table 1). This incidence was not significantly different between the three regional populations. Importantly, due to the high frequency of the CYP2C19 variants in the Iruna population, wild-type (EM) individuals $(* 1 / * 1$; c.681 G/G and c.636 G/G) were in the minority, at 6.4 per cent (Table 1 ).

The Iruna population had a lower CYP2C19*2 frequency compared with East Sepik (0.37 vs 0.45) 


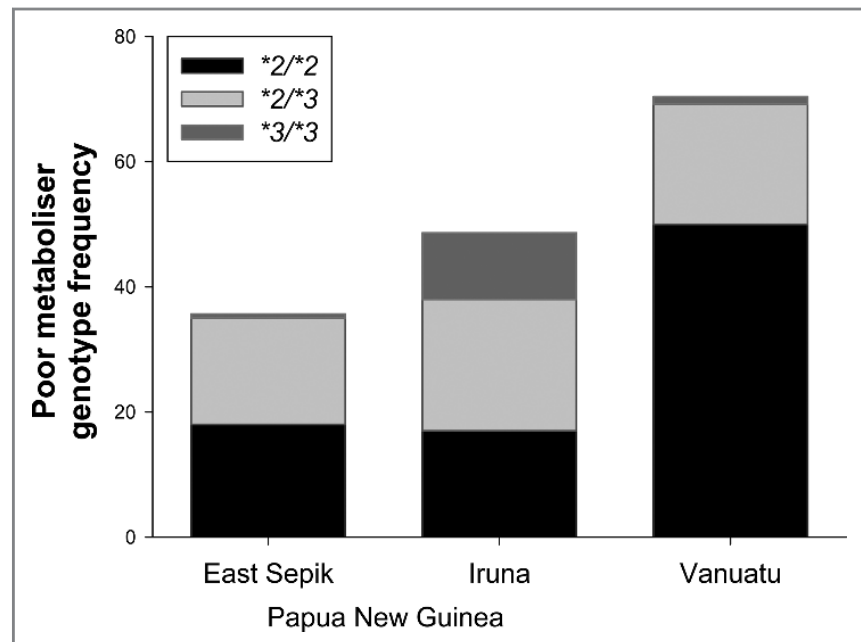

Figure 2. Comparison of the poor metaboliser genotype frequency and pattern of CYP2C19 variant genotypes in Papua New Guinea and Vanuatu. East Sepik ${ }^{12}$ data and Vanuatu data ${ }^{7}$ are as previously reported.

but had a significantly higher CYP2C19*3 frequency $(0.34$ vs $0.16 ; p<0.0001)$. Due to the differences in sample size between the two populations ( $n=47$ vs $n=401$ ), however, the overall incidence of the PM genotype was not statistically different between the Iruna and the East Sepik populations (48.9 per cent vs 36 per cent).

\section{Discussion}

The RFLP-PCR analysis of CYP2C19 variant alleles in whole blood is a widely used and well validated method. ${ }^{17}$ We have adapted this assay for determination of the CYP2C19 genotype from archival serum using published methods for DNA extraction from serum. ${ }^{16}$ Direct DNA sequencing of random samples was also undertaken, as a rare variant, which overlaps with the BamHI recognition sequence in exon 4 , can result in a misclassification of the CYP2C19*3 variant when using RFLP analysis. ${ }^{18}$ There was agreement between the DNA sequence and the RFLP assignment for all the samples tested.

A high incidence (36 per cent) of the CYP2C19 genetic polymorphism has been reported previously in the East Sepik province of PNG. ${ }^{12}$ This is lower than the incidence predicted by Kaneko et al.
( $>74$ per cent), however, based on the observed high frequency of CYP2C19 variants in Vanuatu. ${ }^{7,19,20}$

Colonisation of the Pacific Islands is believed to have involved migration from South-east Asia, via PNG, through Melanesia and Micronesia into Polynesia. ${ }^{8-11}$ The first migration wave is believed to have been from South-east Asia to PNG about 40,000 years ago, with a second wave of migration that extended into the Pacific (Remote Oceania) during the past 3,500 years. Thus, the high prevalence of variant CYP2C19 in Vanuatu may be due to genetic drift rather than a high incidence of the polymorphism in the migrating founder population. Alternatively, as PNG is a country of large ethnic diversity and comprises many geographically isolated populations, another PNG population may be the source of the high incidence of CYP2C19 variants in Vanuatu.

The present study has confirmed the high CYP2C19*2 and CYP2C19*3 allele frequency observed by Masta et al. ${ }^{12}$ in an additional population that is geographically distant (Central province, south-east coast) from East Sepik (Northern Province). There is a significantly higher incidence of the CYP2C19*3 (c.636 G > A) variant allele in the Iruna population compared with the East Sepik population (0.34 vs 0.16). ${ }^{12}$ The frequency of this variant allele was also originally reported to be low (0.133) in Vanuatu. ${ }^{7,19}$ A more detailed analysis of 24 island populations of Vanuatu, ${ }^{20}$ however, demonstrated considerable variability in the incidence of the CYP2C19*3 (c.636 G>A) variant allele (0.020.33). The $* 3$ allele is absent in Caucasian populations ${ }^{5}$ but is found in Asian populations at a frequency of $0.045-0.156 .^{21}$ To our knowledge, the highest incidence of the CYP2C19*3 allele reported is in Indonesian populations of south-east Asia $(0.37) ;^{22}$ thus, the frequency of the $* 3$ allelic variant in the Iruna population of PNG is one of the highest reported to date.

Although the incidence of homozygous *2 and *3 variants in this study was very high, no individuals homozygous for both allelic variants (ie c.681 A/A \& c.636 A/A) were observed in any of the samples analysed. This supports the independent segregation of the two variant alleles, as reported previously. ${ }^{4}$ 
Moreover, the $* 2$ allele frequency is consistently higher than the $* 3$ allele in Asian populations, ${ }^{21}$ East Sepik, ${ }^{12}$ Vanuatu $^{20}$ and also the Iruna region of PNG in the present study. The combination of a high $* 2$ and $* 3$ allele frequency in the Iruna population of PNG, however, results in a high incidence of genotypic PMs (48.9 per cent). This PM incidence is intermediate between that reported for Indonesia (34 per cent ${ }^{22}$ ) and for Vanuatu (61.070.5 per cent $\left.^{7,20}\right)$ but higher than that reported previously for PNG (36 per cent ${ }^{12}$ ). 10.6 per cent of the Iruna population were homozygous $* 3 / * 3$, whereas these individuals are absent or have a low incidence in East Sepik $\left(0-2\right.$ per cent $\left.{ }^{12}\right)$ and Vanuatu (1.2 per cent; ${ }^{7}$ Figure 2 ). Throughout the Vanuatu archipelago, there is considerable variability in the incidence of $* 3 / * 3$ individuals $(0.0-16.0$ per cent), with the majority of islands having a $* 3 / * 3$ incidence of $<0.5$ per cent. ${ }^{20}$ The incidence of the $* 2 / * 2$ genotype is also highly variable within the archipelago (16-63 per cent). This large variability may be the consequence of the relative isolation of these island populations. Similarly, the high incidence of $* 3 / * 3$ individuals in Iruna compared with the East Sepik population may also be the consequence of genetic drift of a relatively isolated population. Importantly, the differences in the incidence of not only the CYP2C19 PM genotype, but also the CYP2C19*3 allelic variant in the Iruna and East Sepik populations of PNG indicate that neither population is a likely 'source' of a founder population responsible for the high incidence of CYP2C19 variants in Vanuatu.

An increased incidence of genetic variants of another drug metabolising enzyme, CYP2B6, has also been reported in PNG. Compared with Caucasian populations, the incidence of the CYP2B6*6 variant is increased in PNG $(0.28$ versus 0.62 , respectively), with a number of other, rarer variants observed at a low frequency, similar to that found in Caucasians. ${ }^{23}$ By contrast, the incidence of the CYP2C $8^{*} 1$ variant is reported to be low or non-existent in 285 individuals so far studied. ${ }^{23}$

The results of the present study confirm the relatively high incidence of CYP2C19 variants in
PNG reported previously. ${ }^{12}$ The relatively high CYP2C19 PM incidence in PNG could have profound consequences for the clearance of many drugs which are metabolised by this enzyme, including the anti-malarial drug proguanil., ${ }^{1,24}$

If the increased frequency of the CYP2C19*2 variant allele observed in Vanuatu occurred early in the colonisation of Remote Oceania, the other island populations of Polynesia and Micronesia may also have high PM frequencies. Relatively little is known about the CYP2C19 genetic status of Pacific Island populations. Phenotypic studies in New Zealand Maori of 'mixed racial background with Caucasian parentage, ${ }^{25}$ and South Pacific Islanders who 'considered themselves to be $>75$ per cent Polynesian', ${ }^{26}$ however, indicate a PM incidence of 7 per cent and 13.6 per cent, respectively. Further studies to determine the incidence of the CYP2C19 PM genotype in these populations is warranted, as this enzyme is involved in the metabolism of an increasing list of drugs and the medical consequences in these populations may be important.

\section{Acknowledgments}

We would like to thank Dr Brian Browning for advice and help with the statistical analysis, Dr Peter Strang for assistance in obtaining samples from Iruna and Dr Nick Thompson, who provided linguistic information for the regional populations. Funding for this work was provided by the University of Auckland New Staff Research Fund.

\section{References}

1. Ward, S.A., Helsby, N.A., Skjelbo, E. et al. (1991), 'The activation of the biguanide antimalarial proguanil co-segregates with the mephenytoin oxidation polymorphism - A panel study', Br. J. Clin. Pharmacol. Vol. 31, pp. $689-692$.

2. Andersson, T., Regardh, C.-G., Lou, Y.-C. et al. (1992), 'Polymorphic hydroxylation of S-mephenytoin and omeprazole metabolism in Caucasian and Chinese subjects', Pharmacogenetics Vol. 2, pp. 25-31.

3. Desta, Z., Zhao, X.-J., Shin, J.-G. and Flockhart, D.A. (2002), 'Clinical significance of the cytochrome P4502C19 genetic polymorphism', Clin. Pharmacokinet. Vol. 41, pp. 913-958.

4. de Morais, S.M., Wilkinson, G.R., Blaisdell, J. et al. (1994), 'Identification of a new genetic defect responsible for the polymorphism of (S)-mephenytoin metabolism in Japanese', Mol. Pharmacol. Vol. 46, pp. $594-598$.

5. Xie, H.-G., Stein, C.M., Kim, R.B. et al. (1999), 'Allelic, genotypic and phenotypic distributions of S-mephenytoin hydroxylase (CYP2C19) in healthy Caucasian populations of European descent throughout the world', Pharmacogenetics Vol. 9, pp. 539-549. 
6. Kubota, K., Chiba, K. and Ishizaki, T. (1996), 'Genotyping of S-mephenytoin $4^{\prime}$-hydroxylation in an extended Japanese population', Clin. Pharmacol. Ther. Vol. 60, pp. 661-666.

7. Kaneko, A., Kaneko, O., Taleo, G. et al. (1997), 'High frequencies of CYP2C19 mutations and poor metabolism of proguanil in Vanuatu', Lancet Vol. 349, pp. 921-922.

8. Green, R.C. (2003), 'The Lapita horizon and traditions - Signature for one set of oceanic migrations', In: Sand, C. (ed.), Pacific Archaeology: Assessments and Prospects. Proceedings of the International Conference for the 50th Anniversary of the First Lapita Excavation, Kone-Noumea 2002 Le Cahiers de l'Archeologie en Noumea, Nouvelle-Caledonie, pp. 95-120.

9. Lum, J.K. and Cann, R.L. (2000), 'mtDNA lineage analyses: Origins and migrations of Micronesians and Polynesians', Am. J. Phys. Anthropol. Vol. 113, pp. 151-168.

10. Lum, J.K., Jorde, L. and Schiefenhovel, W. (2002), 'Affinities among Melanesians, Micronesians, and Polynesians: A neutral, biparental genetic perspective', Hum. Biol. Vol. 74, pp. 413-430.

11. Stoneking, M., Jorde, L.B., Bhatia, K. and Wilson, A.C. (1990), 'Geographic variation in human mitochondrial DNA from Papua New Guinea', Genetics Vol. 124, pp. 717-33.

12. Masta, A., Lum, J.K., Tsukahara, T. et al. (2003), 'Analysis of Sepik populations of Papua New Guinea suggests an increase of CYP2C19 nul allele frequencies during the colonization of Melanesia', Pharmacogenetics Vol. 13, pp. 697-700.

13. Ting, A., James, M., Woodfield, D.G. and Morris, P.J. (1972), 'The distribution of HL-A antigens in the coastal populations of Papua New Guinea', Tissue Antigens Vol. 2, pp. 409-414.

14. Woodfield, D.G., Scragg, R.F., Blake, N.M. et al. (1974), 'Distribution of blood, serum protein and enzyme groups among the Fuyuge speakers of the Goilala sub-district', Hum. Hered. Vol. 24, pp. 507-519.

15. Dutton, T., Voorhoeve, C. and Wurm, S.A. (1971), Papers in New Guinea Linguistics No. 15. Pacific Logistics, Canberra, Australia.

16. Stirling, D. (2003), 'DNA extraction from plasma and serum', In: Bartlett, J.M.S. and Stirling, D. (eds), PCR Protocols (2nd edn), Humana Press, Totowa, NJ, pp. 63-93.
17. Goldstein, J.A. and Blaisdell, J. (1996), 'Genetic tests which identify the principal defects in CYP2C19 responsible for the polymorphism in mephenytoin metabolism', Methods Enzymol. Vol. 272, pp. 210-18.

18. Ohkubo, Y., Ueta, A., Ando, N. et al. (2006), 'Novel mutations in the cytochrome P450 2C19 gene: A pitfall of the PCR-RFLP method for identifying a common mutation', J. Hum. Genet. Vol. 51, pp. 118-123.

19. Kaneko, A., Bergqvist, Y., Taleo, G. et al. (1999), 'Proguanil disposition and toxicity in malaria patients from Vanuatu with high frequencies of CYP2C19 mutations', Pharmacogenetics Vol. 9, pp. 317-326.

20. Kaneko, A., Lum, J., Yaviong, L. et al. (1999), 'High and variable frequencies of CYP2C19 mutations: Medical consequences of poor drug metabolism in Vanuatu and other Pacific islands', Pharmacogenetics Vol. 9, pp. 581-590.

21. Yamada, S., Onda, M., Kato, S. et al. (2001), 'Genetic differences in CYP2C19 single nucleotide polymorphisms among four Asian populations', J. Gastroenterol. Vol. 36, pp. 669-672.

22. Yusuf, I., Djojosubroto, M.W., Ikawati, R. et al. (2003), 'Ethnic and geographic distributions of CYP2C19 alleles in the populations of Southeast Asia', Adv. Exp. Med. Biol. Vol. 531, pp. 37-46.

23. Mehlotra, R.K., Ziats, M.N., Bockarie, M.J. and Zimmerman, P.A. (2006), 'Prevalence of CYP2B6 alleles in malaria-endemic populations of West Africa and Papua New Guinea', Eur. J. Clin. Pharmacol. Vol. 62, pp. 267-275.

24. Coller, J., Somogyi, A. and Bochner, F. (1997), 'Association between CYP2C19 genotype and proguanil oxidative polymorphism', Br. J. Clin. Pharmacol. Vol. 43, pp. 659-660.

25. Wanwimolruk, S., Pratt, E., Denton, J., Chalcroft, S., Barron, P. and Broughton, J. (1995), 'Evidence for the polymorphic oxidation of debrisoquine and proguanil in a New Zealand Maori population', Pharmacogenetics Vol. 5, pp. 193-198.

26. Wanwimolruk, S., Bhawan, S., Coville, P. and Chalcroft, S. (1998), 'Genetic polymorphism of debrisoquine (CYP2D6) and proguanil (CYP2C19) in South Pacific Polynesian populations', Eur. J. Clin. Pharmacol. Vol. 54, pp. 431-435. 